\title{
Propriedades térmicas de cinco variedades de café cereja descascado ${ }^{1}$
}

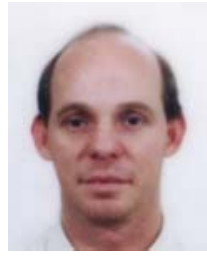

Flávio M. Borém², Ruben C. de M. S. Ribeiro ${ }^{3}$, Paulo C. Corrêa ${ }^{4}$ \& Rosemary G. F. A. Pereira ${ }^{5}$

1 Extraído da Dissertação de Mestrado apresentada pelo segundo autor à Universidade Federal de Lavras - UFLA

2 Departamento de Engenharia, UFLA. CEP 37200-000, Lavras, MG. Fone: (35) 3829-1488. E-mail: borem@ufla.br (Foto)

${ }^{3}$ Departamento de Ciência dos Alimentos - UFLA, MG

4 DEA/UFV. Av. PH Rofs, CEP 36571-000, Viçosa, MG. Fone: (31) 3899-2734. E-mail: copace@ufv.br

5 Departamento de Ciência dos Alimentos, UFLA. Fone: (35) 3829-1405. E-mail: rosegfap@ufla.br

Protocolo $12-6 / 2 / 2002$

\begin{abstract}
Resumo: Este trabalho foi desenvolvido com o objetivo de se determinar, experimentalmente, os valores do calor específico, da condutividade térmica e da difusividade térmica de cinco diferentes variedades de café (Catuaí, Catucaí Vermelho, Catucaí Amarelo, Acaiá e Rubi) em pergaminho e avaliar sua interação com diferentes níveis de umidade. Para determinação do calor específico, utilizou-se o método das misturas. A condutividade térmica foi determinada por meio de um equipamento experimental baseado no método do cilindro teoricamente infinito e na hipótese de condução unidimensional, na direção radial, do calor gerado por um fio condutor. A difusividade térmica foi definida pelo método indireto, utilizando-se os valores obtidos para a massa específica aparente, calor específico e condutividade térmica. Os valores observados foram submetidos à análise de regressão. A partir dos resultados obtidos, observou-se que os dados de calor específico e de condutividade térmica se ajustaram melhor a uma equação polinomial do segundo grau crescente, enquanto os valores da difusividade térmica se adequaram melhor a uma equação de segundo grau decrescente, em relação ao aumento do teor de água para todas as variedades estudadas. Não foi possível ajustar-se, para cada uma das propriedades térmicas, um modelo matemático único para as cinco variedades estudadas, indicando haver efeito da interação teor de água e variedade.
\end{abstract}

Palavras-chave: calor específico, condutividade térmica, difusividade térmica

\section{Thermal properties of five varieties of coffee in parchment}

\begin{abstract}
This research was developed with the objective to determine, experimentally, the values of specific heat, thermal conductivity and thermal diffusivity for five different varieties of coffee (Catuaí, Catucaí Vermelho, Catucaí Amarelo, Acaiá and Rubi) in parchment and evaluate their interaction with different moisture contents. The mixture method was used for the determination of the specific heat. The thermal conductivity was determined using experimental equipment based on the theoretically infinite cylinder method and uni-dimensional conduction hypothesis. The thermal diffusivity was determined by the indirect method using the values obtained for the specific mass, specific heat and thermal conductivity. The observed values were submitted to a regression analysis. The values of specific heat and thermal conductivity of coffee in parchment were best-fitted to a positive second-degree polynomial equation while the thermal diffusivity was best-fitted to a negative second-degree polynomial equation in relation to moisture content for all varieties. It was not possible to adjust for each thermal property a single mathematical model for all the five varieties studied which points out an interactive effect of the moisture content and the varieties.
\end{abstract}

Key words: specific heat, thermal conductivity, thermal diffusivity

\section{INTRODUÇÃO}

Depois de colhido, o café tem sido processado de formas distintas: mantendo-se o fruto intacto (café em coco); removendose apenas a casca e a polpa (descascado); removendo-se a casca, a polpa e a mucilagem, mecanicamente (desmucilado); ou se removendo a mucilagem, por meio de fermentação controlada após remoção da casca e polpa (despolpado). A opção recente pelo processamento do café cereja descascado se deve tanto à redução que representa na área ocupada no terreiro aumentando, assim, sua capacidade de processamento como, também, segundo Dias \& Barros (1993) à melhoria de qualidade e redução do custo de secagem. 
Durante seu processamento e armazenamento, o café passa por várias etapas, em que sua temperatura e umidade podem sofrer alterações. Conhecer como essas alterações ocorrem e saber controlá-las, é fundamental para garantir maior eficiência nos processos e melhor qualidade no produto final. Apesar do desenvolvimento tecnológico obtido até o momento, algumas operações empregadas no manuseio do café precisam ser ainda entendidas com maiores detalhes como, por exemplo, os fenômenos que regem as propriedades químicas e termofísicas dos materiais biológicos. Propriedades como o calor específico, condutividade térmica e difusividade térmica, são relevantes em estudos de transferência de calor e massa de grãos agrícolas.

Para a determinação da quantidade de energia requisitada nos processos de aquecimento e resfriamento de alimentos, é imprescindível o conhecimento do calor específico que, por definição, é a quantidade de calor necessária para elevar a temperatura de um corpo de $1{ }^{\circ} \mathrm{C}$, por unidade de massa, sem mudança de estado. Segundo Montoya et al. (1990) e Pabis et al. (1998) o valor do calor específico depende do produto e do seu conteúdo de água, e pode ser calculado a partir de equações polinomiais de primeiro grau. Para a variedade Colômbia, Montoya et al. (1990) obtiveram a seguinte equação:

$$
\mathrm{Cp}=1,3556+5,7859 \mathrm{U}
$$

em que:

$$
\begin{array}{ll}
\mathrm{Cp} & \text { - calor específico }\left(\mathrm{kJ} \mathrm{kg}^{-1} \mathrm{~K}^{-1}\right) \\
\mathrm{U} & \text { - teor de água (b.s.) }
\end{array}
$$

Toda vez em que houver uma diferença de temperatura num meio, ou entre vários meios, a transferência de calor ocorrerá obrigatoriamente. Segundo Incropera \& De Witt (1996) a condutividade térmica representa a propriedade que relaciona a taxa com que o fluxo de calor escoa através do material, em função da existência de um gradiente de temperatura. A condutividade térmica de um material é a medida da sua capacidade para conduzir calor; nos alimentos, ela depende principalmente, da composição, mas também, da presença de espaços vazios e de sua homogeneidade.

A taxa na qual o calor é difundido, para fora ou para dentro da camada porosa de material agrícola, depende das propriedades térmicas do produto, dentre elas a difusividade térmica, e o gradiente de temperatura no interior do corpo e entre a superfície e o meio ambiente. Segundo Mohsenin (1975) pode ser determinada indiretamente, utilizando-se a relação entre a condutividade térmica, calor específico e massa específica, por meio da Eq. 2.

$$
\alpha=\mathrm{K} /\left(\rho \mathrm{C}_{\mathrm{p}}\right)
$$

em que:

$\alpha \quad$ - difusividade térmica $\left(\mathrm{m}^{2} \mathrm{~s}^{-1}\right)$

$\mathrm{K}$ - condutividade térmica $\left(\mathrm{W} \mathrm{m}^{-1}{ }^{\circ} \mathrm{C}^{-1}\right.$, sendo $\left.\mathrm{W}=\mathrm{J} \mathrm{s}^{-1}\right)$

$\mathrm{Cp}$ - calor específico à pressão constante $\left(\mathrm{kJ} \mathrm{kg}^{-1}{ }^{\circ} \mathrm{C}^{-1}\right)$

$\rho$ - massa específica $\left(\mathrm{kg} \mathrm{m}^{-3}\right)$

A partir da Eq.2, conclui-se que uma relação linear entre a difusividade térmica e teor de água de um sólido não deve ser esperada, também confirmado por Kazarian \& Hall (1965). Além disso, pode-se concluir, ainda, que a amplitude da difusividade térmica influencia a cinética de secagem.

Afonso Júnior \& Corrêa (2000) estudando a massa de grão de café, preparado por via seca e úmida, observaram que os valores da difusividade térmica para o café descascado variaram de $1,357 \times 10^{-7} \mathrm{a} 1,699 \times 10^{-7} \mathrm{~m}^{2} \mathrm{~s}^{-1}$, para teores de água entre 0,111 a 0,597 (b.s.). Para o café em coco, a difusividade térmica alterou de $1,0694 \times 10^{-7} \mathrm{a} 1,5441 \times 10^{-7} \mathrm{~m}^{2} \mathrm{~s}^{-1}$, para teores de água entre 0,111 a 0,678 (b.s.) enquanto, para o café despolpado a difusividade térmica sofreu variação de $1,344 \mathrm{x}$ $10^{-7} \mathrm{a} 2,078 \times 10^{-7} \mathrm{~m}^{2} \mathrm{~s}^{-1}$, para teores de água variando de 0,111 a 0,621 (b.s.). Os autores relatam, também, que não há diferenças acentuadas no comportamento das formas analisadas de preparo do café descascado contendo ou não a parte da mucilagem, o que pouco interfere nas propriedades termofísicas do produto.

Considerando-se a franca expansão do uso do cereja descascado no processamento do café, suas vantagens em relação à melhoria de qualidade e redução de custos e a escassez de literatura referente às propriedades térmicas relatadas para café descascado buscou-se, por meio deste trabalho, determinar as variações dos valores de calor específico, condutividade térmica e difusividade térmica de cinco diferentes variedades de café cereja descascado, em função do teor de água.

\section{MATERIAL E MÉTODOS}

O presente trabalho foi desenvolvido na Universidade Federal de Lavras (UFLA) e no Laboratório de Propriedades Físicas e Avaliação de Qualidade de Produtos Agrícolas do Centro Nacional de Treinamento em Armazenagem "CENTREINAR", situado no Campus da Universidade Federal de Viçosa, MG. Foram avaliados o calor específico, a condutividade térmica e a difusividade térmica de cinco variedades de café cereja descascado, mantendo-se a temperatura ambiente constante de $20^{\circ} \mathrm{C}$.

Cerca de $500 \mathrm{~L}$ de café (Coffea arabica L.) das variedades Acaiá, Rubi, Catuaí, Catucaí Amarelo e Catucaí Vermelho, com umidade média de $55 \%$ b.u., foram colhidos manualmente sobre pano, no setor de cafeicultura da UFLA. Após a colheita, o café de cada uma das variedades foi lavado e separado em café bóia, verde e cereja. A porção formada pelo café cereja foi descascada em um descascador mecânico, em seguida acondicionada em sacos de polietileno trançado e colocada em terreiro de cimento, para remoção do excesso de água. Amostras de cada variedade foram retiradas para determinação do teor de água. Para evitar possíveis alterações no café em função do seu alto teor de água, todo o material foi acondicionado em sacos plásticos e mantido em câmara fria a $5^{\circ} \mathrm{C}$.

Cerca de $5 \mathrm{~kg}$ de café úmido, de cada uma das variedades, foram colocados em estufa com ventilação forçada e temperatura constante de $60^{\circ} \mathrm{C}$, para se obter nove diferentes níveis de umidade.

O teor de água foi determinado usando-se o método padrão de estufa a $105 \pm 3^{\circ} \mathrm{C}$, durante $24 \mathrm{~h}$ (Brasil, 1992). 
Para a determinação do calor específico da massa de grãos de café cereja descascado, utilizou-se o método da mistura direta, que consiste no emprego de um recipiente isolado com lã de vidro (calorímetro) de capacidade calorífica conhecida, com um líquido inerte (Kazarian \& Hall,1965; Mohsenin, 1980). A amostra de café, a uma temperatura diferente do líquido calorimétrico (água), foi posta no calorímetro à pressão constante e temperatura ambiente de $20{ }^{\circ} \mathrm{C}$. Foram realizadas três repetições para cada tratamento. Atingido o equilíbrio térmico, o calor específico do produto foi calculado, utilizando-se a Eq. 3.

$$
\mathrm{C}_{\mathrm{p}} \mathrm{m}_{\mathrm{p}}\left(\mathrm{T}_{5}-\mathrm{T}_{4}\right)=\mathrm{C}_{\mathrm{a}}\left(\mathrm{m}_{1}+\mathrm{m}_{2}\right)\left(\mathrm{T}_{3}-\mathrm{T}_{5}\right)+\mathrm{C}_{\mathrm{cal}}\left(\mathrm{T}_{3}-\mathrm{T}_{5}\right)
$$

em que:

$$
\begin{array}{ll}
\mathrm{C}_{\mathrm{p}} & \text { - calor específico do produto }\left(\mathrm{kJ} \mathrm{kg}^{-1}{ }^{\circ} \mathrm{C}^{-1}\right) \\
\mathrm{C}_{\mathrm{a}} & \text { - calor específico da água }\left(\mathrm{kJ} \mathrm{kg}^{-1}{ }^{\circ} \mathrm{C}^{-1}\right) \\
\mathrm{C}_{\mathrm{cal}} & \text { - capacidade calorífica do calorímetro }\left(\mathrm{kJ}^{\circ} \mathrm{C}^{-1}\right) \\
\mathrm{m}_{\mathrm{p}} & \text { - massa de produto }(\mathrm{kg}) \\
\mathrm{m}_{1} & \text { - massa da água quente }(\mathrm{kg}) \\
\mathrm{m}_{2} & \text { - massa da água fria }(\mathrm{kg}) \\
\mathrm{T}_{4} & \text { - temperatura do produto }\left({ }^{\circ} \mathrm{C}\right) \\
\mathrm{T}_{3} & \text { - temperatura de equilíbrio da água }\left({ }^{\circ} \mathrm{C}\right) \\
\mathrm{T}_{5} & \text { - temperatura de equilíbrio (água e produto })\left({ }^{\circ} \mathrm{C}\right)
\end{array}
$$

Para determinação da condutividade térmica da massa granular de café, utilizou-se um equipamento experimental baseado no método do cilindro teoricamente infinito e na hipótese de condução unidimensional, na direção radial, do calor gerado por um fio condutor, segundo metodologia descrita por Muir \& Chandra (1970). Antes da determinação da condutividade térmica, as amostras foram colocadas em câmara B.O.D., na qual se encontrava o cilindro, até temperatura constante. Após o equilíbrio térmico entre o ambiente e o produto, preencheu-se o cilindro com o material a ser analisado. Por um fio resistor localizado no eixo central do cilindro, fez-se passar uma corrente com amperagem de 1,05 A e voltagem de aproximadamente $2,9 \mathrm{~V}$, gerada por um regulador de tensão localizado no exterior do cilindro. Seis termopares de cobreconstantan foram dispostos radialmente no interior do cilindro e distantes um centímetro entre si. As extremidades dos termopares foram conectadas a um termômetro digital.

A equação que governa a transferência transiente de calor em um cilindro infinito quando se considera uma geração de calor proveniente de uma fonte infinita central com diâmetro zero e potência constante, em um meio infinito e homogêneo com condições iniciais isotérmicas e em equilíbrio com o ambiente, pode ser expressa como (Mohsenin, 1980):

$$
\frac{\partial \mathrm{T}}{\partial \mathrm{t}}=\alpha\left(\frac{\partial^{2} \mathrm{~T}}{\partial \mathrm{r}^{2}}+\frac{1}{\mathrm{r}} \frac{\partial \mathrm{T}}{\partial \mathrm{r}}\right)
$$

em que:

$\mathrm{T}$ - temperatura $\left({ }^{\circ} \mathrm{C}\right)$

t $\quad$ - tempo de aquecimento da amostra (s)

$\alpha \quad$ - difusividade térmica $\left(\mathrm{m}^{2} \mathrm{~s}^{-1}\right)$

r $\quad$ - raio de localização do termopar (m)
Desenvolvendo-se a Eq. 4, obtém-se:

$$
\mathrm{K}=\frac{\mathrm{Q}}{4 \pi\left(\mathrm{T}_{\mathrm{f}}-\mathrm{T}_{\mathrm{i}}\right)} \ln \left(\frac{\theta_{2}-\theta_{0}}{\theta_{1}-\theta_{0}}\right)
$$

em que:

$\mathrm{K}$ - condutividade térmica $\left(\mathrm{W} \mathrm{m} \mathrm{m}^{-1} \mathrm{C}^{-1}\right)$

Q - potência dissipada pela fonte, por unidade de comprimento $\left(\mathrm{W} \mathrm{m}^{-1}\right)$

$\mathrm{T}_{\mathrm{f}} \quad$ - temperatura final do intervalo usado $\left({ }^{\circ} \mathrm{C}\right)$

$\mathrm{T}_{\mathrm{i}} \quad$ - temperatura inicial do intervalo usado $\left({ }^{\circ} \mathrm{C}\right)$

$\theta_{2}$ - instante final do intervalo usado para determinar a condutividade térmica (s)

$\theta_{1} \quad$ - instante inicial do intervalo usado para determinar a condutividade térmica ( $\mathrm{s}$ )

$\theta_{\mathrm{o}} \quad$ - fator de correção de tempo (s)

A condutividade térmica da massa dos grãos de café foi obtida em regime transiente, a partir da Eq. 5, de acordo com Muir \& Chandra (1970) e Chang (1986).

Para a obtenção do fator de correção $\theta$, fez-se a regressão dos incrementos de temperatura, em função do logaritmo natural dos intervalos de tempo. O valor do termo de correção de tempo $\theta_{0}$ foi determinado utilizando-se o arredondamento exponencial dos valores $\left(\mathrm{e}^{\mathrm{a} / \mathrm{b}}\right)$ obtidos a partir da equação de regressão para cada repetição da determinação da condutividade térmica, conforme descrito por Afonso Júnior \& Corrêa (2000).

A difusividade térmica foi definida indiretamente pela Eq. 2, usando-se os valores experimentais encontrados para a massa específica aparente (Ribeiro et al., 2001) calor específico e condutividade térmica.

Os dados foram submetidos a análises estatísticas quantitativas, determinando-se as equações de regressão a 95\% de confiabilidade, com base nos coeficientes de determinação $\left(\mathrm{R}^{2}\right)$ apresentados, objetivando-se caracterizar a natureza e o comportamento da curva de resposta destas, em função dos tratamentos propostos. As análises de regressão foram precedidas de uma análise de variância, a fim de comprovar estatisticamente se os dados apresentavam ou não diferença significativa entre os tratamentos. Utilizou-se o delineamento inteiramente casualizado (DIC) em três repetições, com um fator variante (teor de água) nos nove níveis de umidade.

O modelo de regressão foi apresentado por:

$$
Y i j=a+b x j+c x j^{2}+d i j
$$

em que:

i $\quad-1,2,3,4$ e 5, para cada parcela

a, b, e c - coeficientes de regressão

dij - efeito do desvio de regressão

xj - i-ésimo teor de água

Yij - média do j-ésimo teor de água

Todas as análises foram realizadas através do programa SISVAR 4.0, segundo Ferreira (2000). 


\section{RESULTADOS E DISCUSSÃO}

Na Tabela 1 são apresentados os resultados da análise de variância do efeito das variedades e do teor de água sobre o calor específico, a condutividade térmica e a difusividade térmica de café cereja descascado. Observa-se que a interação variedade $\mathrm{x}$ teor de água afetou significativamente, no nível de 0,05 de probabilidade, os valores das propriedades térmicas, não sendo possível ajustar-se uma única equação para explicar as variações constatadas. Buscou-se, então, ajustar equações separadamente, para cada uma das variedades estudadas.

Tabela 1. Resumo da análise de variância do calor específico e condutividade térmica para cinco variedades de café cereja descascado e nove teores de água

\begin{tabular}{|c|c|c|c|c|}
\hline \multirow[b]{2}{*}{$\begin{array}{l}\text { Fonte de } \\
\text { Variação }\end{array}$} & \multirow[b]{2}{*}{ GL } & \multicolumn{3}{|c|}{ Quadrados Médios } \\
\hline & & $\begin{array}{c}\text { Calor } \\
\text { Específico }\end{array}$ & $\begin{array}{c}\text { Condutividade } \\
\text { Térmica }\end{array}$ & $\begin{array}{l}\text { Difusividade } \\
\text { Térmica }\end{array}$ \\
\hline Variedade (V) & 4 & 0,314293 & $0,000250 *$ & $0,006039 *$ \\
\hline Teor de água (T) & 8 & 1,126627 & $0,001925^{*}$ & $0,038262 *$ \\
\hline $\mathrm{Vx} \mathrm{T}$ & 32 & 0,314293 & $0,000250 *$ & $0,0007289^{*}$ \\
\hline Resíduo & 90 & 0,011267 & 0,000037 & 0,000170 \\
\hline C. V. (\%) & & 5,88 & 4,50 & 7,47 \\
\hline
\end{tabular}

Após a secagem em diferentes variedades, foram obtidos os níveis de umidade (b.s.) variando entre 0,0995 e 0,9505, usados para o ajuste das equações.

Considerando-se que tanto os polinômios de primeiro como os de segundo graus são modelos simples e explicam satisfatoriamente as variações das propriedades térmicas estudadas em função do teor de água, usou-se o critério de maior coeficiente de ajuste $\left(\mathrm{R}^{2}\right)$ para a escolha da equação a ser adotada.

Os valores observados e estimados do calor específico e da condutividade térmica, bem como as equações ajustadas, são apresentados, respectivamente, nas Figuras 1 e 2. Observase que tanto o calor específico como a condutividade térmica, tenderam a um aumento com a elevação do teor de água para todas as variedades estudadas, confirmando os resultados relatados por Afonso Júnior \& Corrêa (2000) e por Montoya et al. (1990).

Constata-se que, apesar dos valores do calor específico se situarem entre $1,00 \mathrm{e} 3,00 \mathrm{~kJ} \mathrm{~kg}^{-10} \mathrm{C}^{-1}$, e da condutividade térmica entre $0,10 \mathrm{e} 0,20 \mathrm{~W} \mathrm{~m}^{-1}{ }^{\circ} \mathrm{C}^{-1}$ para todas as variedades estudadas nos teores de água entre 0,1 a 0,95 (b.s.) não foi possível ajustarse uma única equação para todas as variedades. Desta forma, modelos teóricos de predição da variação da temperatura do café cereja descascado no armazenamento ou durante a secagem, devem ser ajustados levando-se em consideração a variedade do café.

Os valores obtidos experimentalmente para a difusividade térmica a partir dos dados observados e as equações ajustadas são apresentados na Figura 3, na qual se observa que a difusividade térmica reduziu com o aumento do teor de água, e a equação quadrática foi a que melhor se ajustou aos dados experimentais.

Os valores da difusividade térmica variaram entre $1,0 \times 10^{-7}$ e $3,0 \times 10^{-7} \mathrm{~m}^{2} \mathrm{~s}^{-1}$, para todas as variedades de café cereja
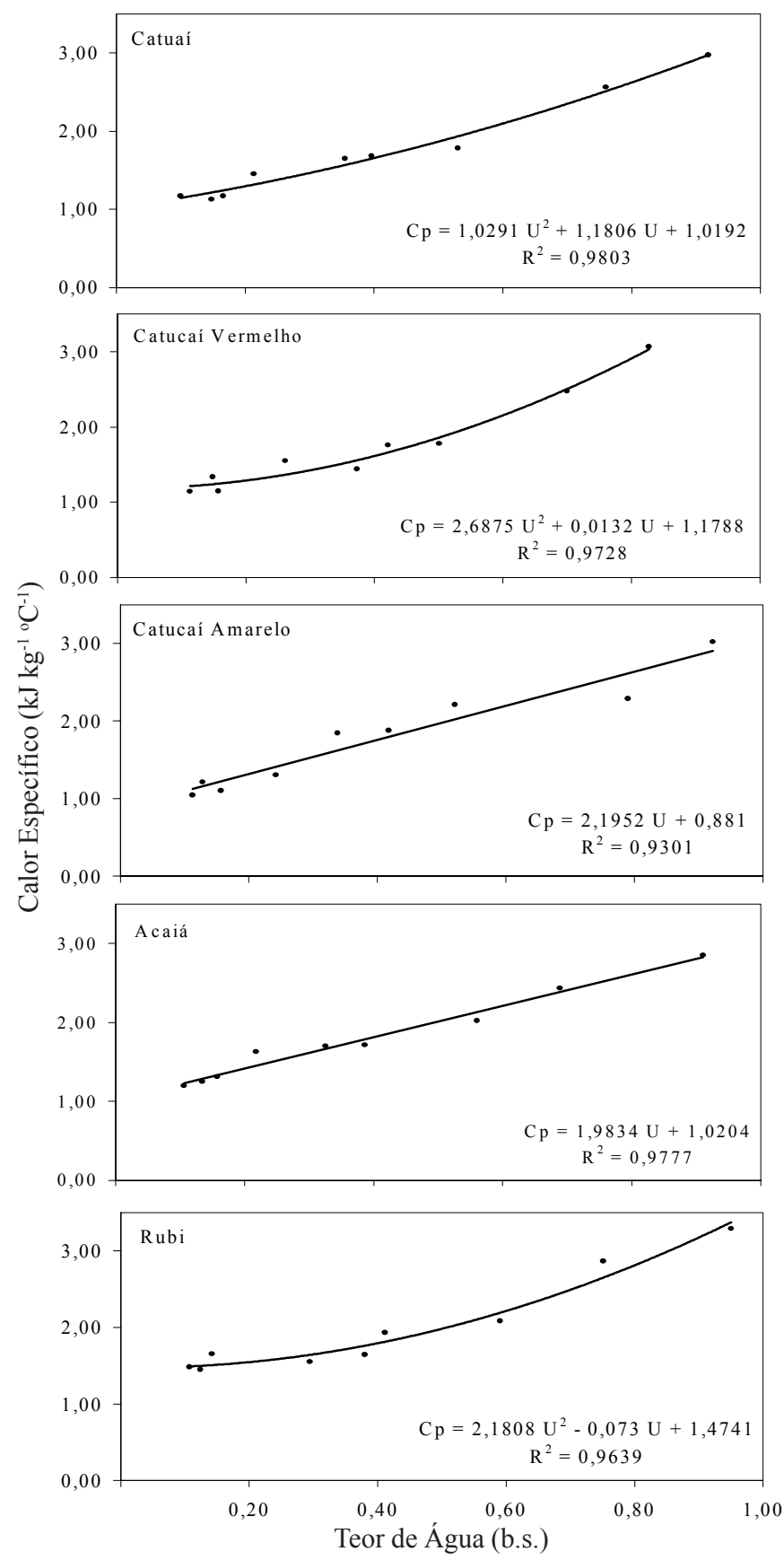

Figura 1. Calor específico da variedade Catuaí, Catucaí Vermelho, Catucaí Amarelo, Acaiá e Rubi, em função do teor de água

descascado, nos teores de água entre 0,1 e 0,95 (b.s.). Relações quadráticas foram descritas por Afonso Júnior \& Corrêa (2000) relatando valores para a difusividade térmica de café na mesma ordem de grandeza que os encontrados neste trabalho. Chandrasekar \& Viswanathan (1999) relatam valores de até 2,36 $\mathrm{x} 10^{-7} \mathrm{~m}^{2} \mathrm{~s}^{-1}$ para a difusividade térmica de frutos de café com 0,11 (b.s.) de teor de água.

Equações descritas por diversos autores para se estimar a difusividade térmica, consideram também a temperatura e a massa específica, além do teor de água de produtos agrícolas (Pabis et al., 1998). Nota-se que, exceto para a cultivar Acaiá, os coeficientes ajustados das equações para a difusividade térmica foram os menores obtidos dentre as propriedades 

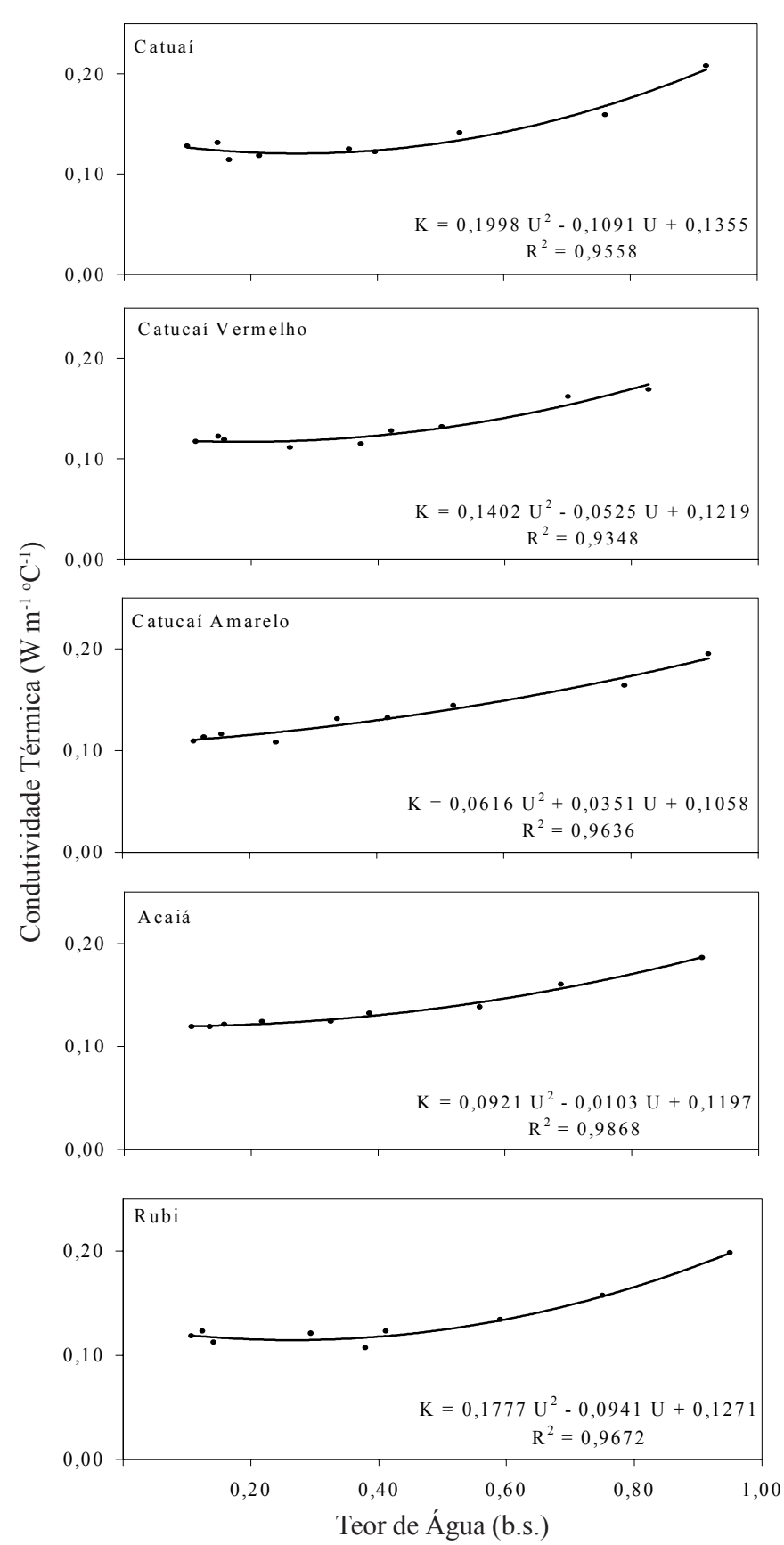

Figura 2. Condutividade térmica das variedades Catuaí, Catucaí Vermelho, Catucaí Amarelo, Acaiá e Rubi, em função do teor de água

estudadas; então, sugere-se que nos estudos subseqüentes, variáveis como a temperatura e massa específica sejam incluídas nos modelos propostos.

\section{CONCLUSÕES}

1. Os valores do calor específico, da condutividade térmica e da difusividade térmica, variaram significativamente $(p<0,05)$ em função das variedades estudadas.

2. Não foi possível ajustar-se uma única equação para cada uma das propriedades térmicas estudadas para todas as variedades, em função do teor de água.
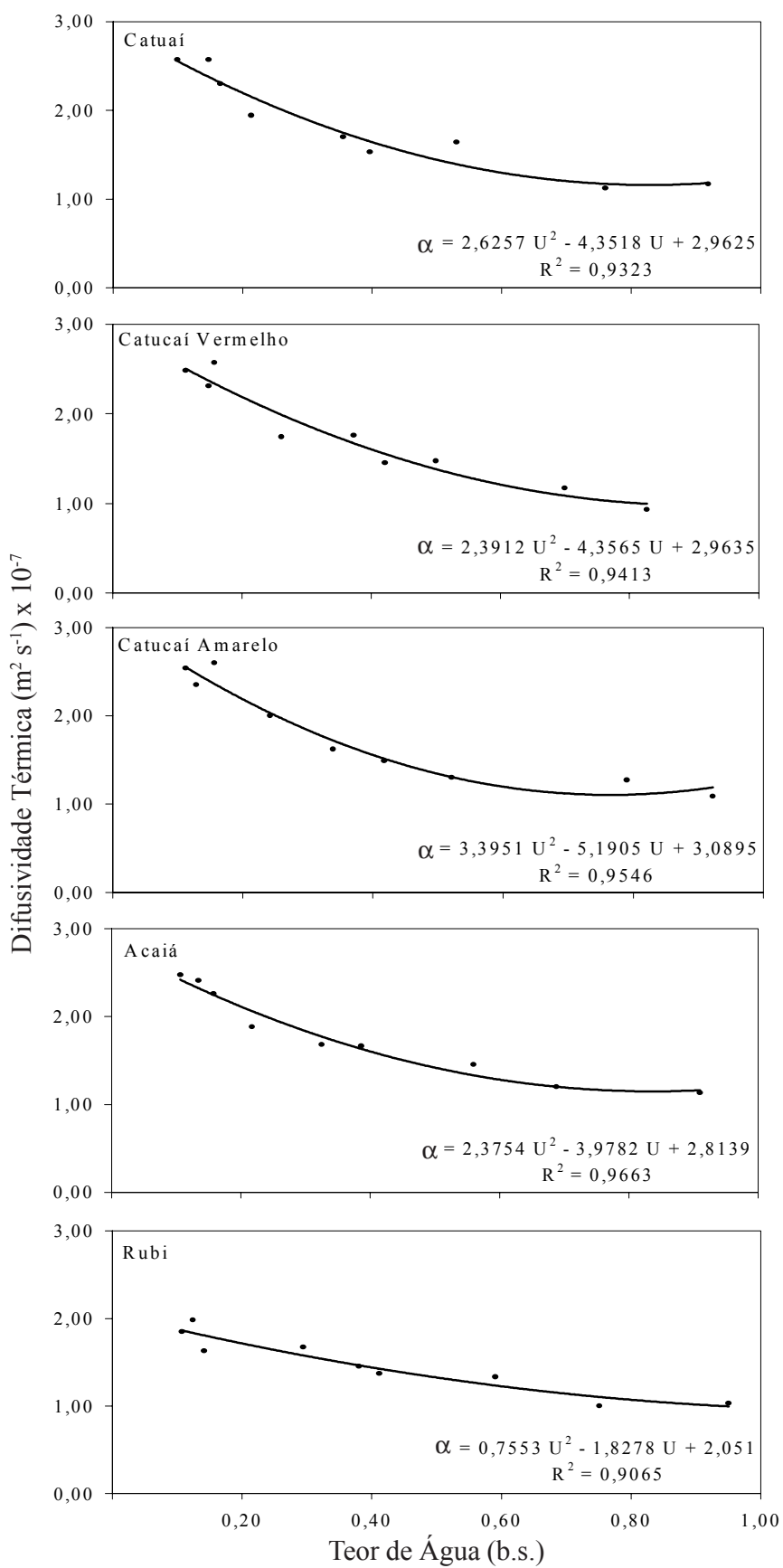

Figura 3. Difusividade térmica das variedades Catuaí, Catucaí Vermelho, Catucaí Amarelo, Acaiá, Rubi, em função do teor de água

3. Os valores do calor específico variaram entre 1,00 e 3,00 $\mathrm{kJ} \mathrm{kg}^{-10} \mathrm{C}^{-1}$, da condutividade térmica entre 0,10 e $0,20 \mathrm{~W} \mathrm{~m}^{-1}{ }^{\circ} \mathrm{C}^{-1}$ e da difusividade térmica entre $1,0 \times 10^{-7}$ e $3,0 \times 10^{-7} \mathrm{~m}^{2} \mathrm{~s}^{-1}$, para todas as variedades de café cereja descascado, nos teores de água entre 0,1 a 0,95 (b.s.).

4. Os valores do calor específico tenderam a aumentar com o aumento do teor de água e se ajustaram melhor a equações polinomiais de primeiro grau para as variedades Catucaí Amarelo e Acaiá, e a equações polinomiais de segundo grau para as variedades Catuaí, Catucaí Vermelho e Rubi.

5. Os valores da condutividade térmica tenderam a aumentar com o crescimento do teor de água, enquanto os 
valores da difusividade térmica diminuíram com o aumento do teor de água, ajustando-se melhor a equações polinomiais de segundo grau para todas as variedades estudadas.

\section{AGRADECIMENTOS}

Os autores agradecem à Coordenação do Programa de Pós-Graduação em Ciências dos Alimentos da Universidade Federal de Lavras, ao CENTREINAR, pelo apoio dado para o desenvolvimento da pesquisa e ao professor Ednilton Tavares de Andrade, da Universidade Federal Fluminense, pelas sugestões.

\section{LITERATURA CITADA}

Afonso Júnior, P.C.; Corrêa, P.C. Propriedades térmicas dos grãos de café. In: Simpósio de Pesquisa dos Cafés do Brasil, 2, 2000, Poços de Caldas. Resumos... Brasília: Embrapa Café, 2000. v.2, p.1142-1146.

Brasil, Ministério da Agricultura e Reforma Agrária. Regras para análise de sementes (RAS), Brasília, 1992. 365p.

Chandrasekar, V.; Viswanathan, R. Physical and thermal properties of coffee. Journal of Agricultural Engineering, New Delhi, n. 73, p.227-234, 1999.

Chang, C.S. Thermal conductivity of wheat, corn, and grain sorghum as affected by bulk density and moisture content. Transactions of the ASAE, St. Joseph, v.29, n.5, p.14471450, 1986.
Dias, M.C.L.L.; Barros, A.S. do R. Avaliação de métodos para remoção da mucilagem de sementes de café (Coffea arabica L.). Revista Brasileira de Sementes, Brasília, v.15, n.2,p.191-195, 1993.

Ferreira, D.F. Análises estatísticas por meio do Sisvar para Windows versão 4.0. In: Reunião Anual da Região Brasileira da Sociedade Internaciaonal de Biometria, 45, 2000, São Carlos. Anais... São Carlos: UFScar, 2000, p.255-258.

Incropera, F.P.; De Witt, D.P. Fundamentals of heat and mass transfer. New York: John Wiley \& Sons, 1996. 886p.

Kazarian, E.A.; Hall, C.W. Thermal properties of grain. Transactions of the ASAE, St. Joseph, v.8, n.1, p.33-38, 1965.

Mohsenin, N.N. Thermal properties of foods and agricultural materials. Part I: Basic concepts and specific heat. Department of Agricultural Engineering. The Pennsylvania State University, 1975.160p.

Mohsenin, N.N. Thermal properties of foods and agricultural materials. New York: Gordon and Breach Science Publishers Inc., $1980.407 \mathrm{p}$

Montoya, E.C.; Oliveiros, T.C.E.; Roa, M.G. Optimización operacional del secador intermitente de flujos concurrentes para café pergamino. Cenicafé, n.41, v.1, p.13-19, 1990.

Muir, W.E.; Chandra, S. Thermal conductivity of spring wheat at low temperatures. Transactions of the ASAE, St. Joseph, n.70, p.805, 1970.

Pabis, S.; Jayas, D.S.; Cenkowski, S. Grain drying: Theory and practice. New York: John Wiley \& Sons, 1998. 303p.

Ribeiro, R.C.M.S; Borém, F.M; Corrêa, P.C.; Ribeiro, D.M; Resende, O. Porosidade e massa específica de cinco variedades de café cereja descascado. Revista Brasileira de Armazenamento, Viçosa, v.3, p.54-61, 2001. Especial - Café 